\title{
Murine FGFR-1 is required for early postimplantation growth and axial organization
}

\author{
Chu-Xia Deng, Anthony Wynshaw-Boris, ${ }^{1}$ Michael M. Shen, ${ }^{2}$ Cathie Daugherty, David M. Ornitz, ${ }^{3}$ \\ and Philip Leder
}

Howard Hughes Medical Institute and Department of Genetics, Harvard Medical School, Boston, Massachusetts 02115 USA

We have explored the role of fibroblast growth factor receptor 1 (FGFR-1) in early embryonic development using three experimental systems: genetically deficient mice, in vitro blastocyst culture, and FGFR-1-deficient embryonic stem cells. Using these systems, we demonstrate that FGFR-1 is required for proper embryonic cell proliferation and for the correct axial organization of early postimplantation embryos but not for mesoderm formation. FGFR-1-deficient embryos display severe growth retardation both in vitro and in vivo and die prior to or during gastrulation. Although these mutants can form nonaxial tissues, such as the allantois, amnion, and yolk sac mesoderm, they display defective patterning of the primitive streak and other axial structures, and frequently exhibit truncations or disorganization of posterior embryonic regions. Such abnormalities are unlikely to be caused by intrinsic blocks in mesodermal differentiation, as FGFR-1-deficient ES cell lines form teratomas consisting of many mesodermal cell types.

[Key Words: Gene targeting; gastrulation; mesoderm induction; pattern formation]

Received September 28, 1994; revised version accepted November 10, 1994.

Fibroblast growth factors (FGFs) constitute a family of at least nine structurally and functionally related growth factors that have been implicated in a variety of important biological processes such as mitogenesis, angiogenesis, cell migration, differentiation, and mesoderm induction (Burgess and Maciag 1989; Klagsbrun 1989; Basilico and Moscatelli 1992). High-affinity receptors (FGFRs) for FGFs comprise a family of at least four transmembrane proteins with intrinsic tyrosine kinase activity (Basilico and Moscatelli 1992; Johnson and Williams 1993). These receptors share common structural features, including a hydrophobic leader sequence, three immunoglobulin-like domains, an acidic region, a transmembrane region, and divided tyrosine kinase domains. Numerous mRNA isoforms of the fgfr genes are generated by alternative splicing in the extracellular, juxtamembrane, and intracellular domains (Johnson et al. 1990; Hou et al. 1991; Johnson et al. 1991; Werner et al. 1992; Xu et al. 1992).

In the mouse, the mRNA expression patterns of FGFs

Present addresses: ${ }^{1}$ Laboratory of Genetic Disease Research, National Center for Human Genome Research, National Institutes of Health, Bethesda, Maryland 20892 USA; $^{2}$ Center for Advanced Biotechnology and Medicine, Department of Pediatrics, University of Medicine and Dentistry of New Jersey/Robert Wood Johnson Medical School, Piscataway, New Jersey 08854 USA; ${ }^{3}$ Department of Molecular Biology and Pharmacology, Washington University School of Medicine, St. Louis, Missouri 63110 USA. and FGFRs have suggested potential roles for these genes in early embryogenesis. Several studies have demonstrated that int-2 (FGF-3) is expressed in early migrating mesoderm and neuroectoderm (Wilkinson et al. 1986; Niswander and Martin 1992), that FGF-4 is expressed in the inner cell mass and early mesoderm (Hébert et al. 1990; Niswander and Martin 1992), and that FGF-5 is expressed in the primitive ectoderm (Haub and Goldfarb 1991; Hébert et al. 1991). Similarly, in situ hybridization studies have shown that $f g f r-1$ and $f g f r-2$ are expressed in gastrulation stage embryos (Orr-Urtreger et al. 1991; Yamaguchi et al. 1992), that $f g f_{r}-3$ is expressed during organogenesis and limb formation (Peters et al. 1993), and that $f g f r-4$ is expressed in the definitive endoderm and the somitic myotome (Stark et al. 1991).

Studies of Xenopus embryogenesis have demonstrated an important role for the FGF signaling pathway in mesoderm formation. In particular, several members of the FGF family have been shown in animal cap assays to induce ventral mesoderm, such as muscle, mesenchyme, and blood (Kimelman and Kirschner 1987; Paterno et al. 1988; Slack et al. 1989; Smith 1989). Conversely, expression of an injected dominant-negative FGFR construct frequently inhibits the formation of ventral and posterior mesoderm in intact embryos (Amaya et al. 1991). Detailed analysis of the effects of this construct in embryos and in animal caps suggests that FGF signaling is essential for many early molecular responses to mesoderm 
induction in Xenopus (Amaya et al. 1993; Cornell and Kimelman 1994; LaBonne and Whitman 1994).

These findings indicate that the FGF signaling pathway is essential for normal embryonic pattern formation. However, such studies have not yet provided a detailed understanding of the roles of individual FGFs and FGFRs in vertebrate development. One approach for investigating this issue is to mutate individual $f g f$ and $f g f_{r}$ loci through targeted gene disruption in mice. For example, targeted mutation of int-2 has revealed essential roles for this gene in inner ear and tail development (Mansour et al. 1993).

As described below, we have created mice that carry germ-line mutations of the fgfr- 1 locus through homologous recombination in embryonic stem (ES) cells. The fgfr-1 gene was mutated by the insertion of a neo gene into its fourth exon, which is shared by all major splice isoforms (Johnson et al. 1991), thereby creating a strong reduction or loss-of-function mutation. The consequences of this mutation are severe, resulting in homozygous lethality before or during gastrulation. Our data demonstrate that signals mediated by FGFR-1 are essential for cell proliferation and axial organization of embryos during postimplantation development.
Results

Targeted disruption of the fgfr-1 gene

To create the fgfr-1 $1^{e \times 4}$ mutation, we generated the targeting construct pFGFRlneo (Fig. 1). This construct contains a $9-\mathrm{kb} f g f r-1$ genomic sequence interrupted in exon 4 by a PGKneo cassette. The fourth exon contains part of the Ig2 domain and part of the hinge connecting the Ig2 and Ig 3 domains, which are shared by all major fgfr-1 splice isoforms (Johnson et al. 1990, 1991; Werner et al. 1992). The neo gene was placed in the opposite orientation relative to that of $f_{g} f_{r}-1$ to introduce stop codons in all three reading frames and to prevent potential readthrough transcription from the $P G K$ promoter. Therefore, the PGKneo insertion should truncate the $f g f_{r}-1$-coding sequence immediately after the $\operatorname{Ig} 2$ domain and should disrupt all major isoforms of the gene.

Three ES clones carrying the targeted $f g f_{r}-1^{e \times 4}$ mutation were injected into $\mathrm{C} 57 \mathrm{Bl} / 6 \mathrm{~J}$ blastocysts to obtain germ-line transmission. Injection of one of these clones, 11-22, generated 12 high-degree chimeras, with 10 males and 2 females. When mated to black female mice $(\mathrm{NIH}$ Black Swiss|, nine of the male chimeras gave agouti
Figure 1. Targeted disruption of the $f_{g} f_{r}-1$ gene. (A) Targeting vector pFGFR lneo contains a 9-kb genomic sequence of the fgfr-1 genomic locus (not drawn to scale). The solid boxes represent fgfr-1 exons, numbered according to the published map (Johnson et al. 1991). The crosshatched box represents $p G K n e o$ inserted at an AatII site in the fourth exon of $f_{g} f_{r-1}$, such that $7 \mathrm{~kb}$ of $5^{\prime}$ and $2 \mathrm{~kb}$ of $3^{\prime}$ sequence flank the insert. The $f g f_{r-1}$ sequences are flanked by copies of the HSV-TK genes (stippled boxes) and the pUC vector (open box). Transcriptional directions of neo and $T K$ are indicated by arrows. The targeting vector was linearized at the unique Sall site prior to electroporation. Homologous recombination within $f g f r-1$ would replace the endogenous exon 4 with $p G K n e o$, creating a bandshift from 9 to $6 \mathrm{~kb}$ upon EcoRV digestion. The DNA probe used for Southern blotting is a 2-kb XhoI-EcoRV fragment, indicated by a solid bar. $(B)$ Targeting vector pFGFR 1 hyg contains a 6-kb EcoRI fragment of fgfr-1. A hyg gene is inserted at the AatII site in the fourth exon of $f g f r-1$. pFGFR 1 hyg was linearized at the Sall site and transfected into 11-22, an ES cell line heterozygous for a targeted allele of $f g f r-1$ generated by pFGFRlneo. Homologous recombination between pFGFRlhyg and the wild-type allele of $f_{g} f_{r}-1$ would replace exon 4 with the $1.5 \mathrm{~kb}$ hyg gene, creating a bandshift from 9 to $10.5 \mathrm{~kb}$ upon EcoRV digestion. $(C)$ Southern blot analysis of targeted cell lines. (Lane 1) DNA from the parental ES cell line; (lane 2) DNA from the 11-22 clone; (lane 3,4) DNA from 23-18 and 23-46, respectively, which are two hyg ${ }^{\prime} /$ FIAU $^{\mathrm{r}}$ clones generated by the pFGFRlhyg targeting vector. Positions of marker fragments at 10.5,9, and $6 \mathrm{~kb}$ are indicated. All DNAs were digested with EcoRV and probed with a radiolabeled $2-\mathrm{kb} X$ hoI and EcoRV fragment. (Aa) AatII; (Ec) EcoRI; (Ev) EcoRV; (Sa) SalI; (Xh) XhoI.
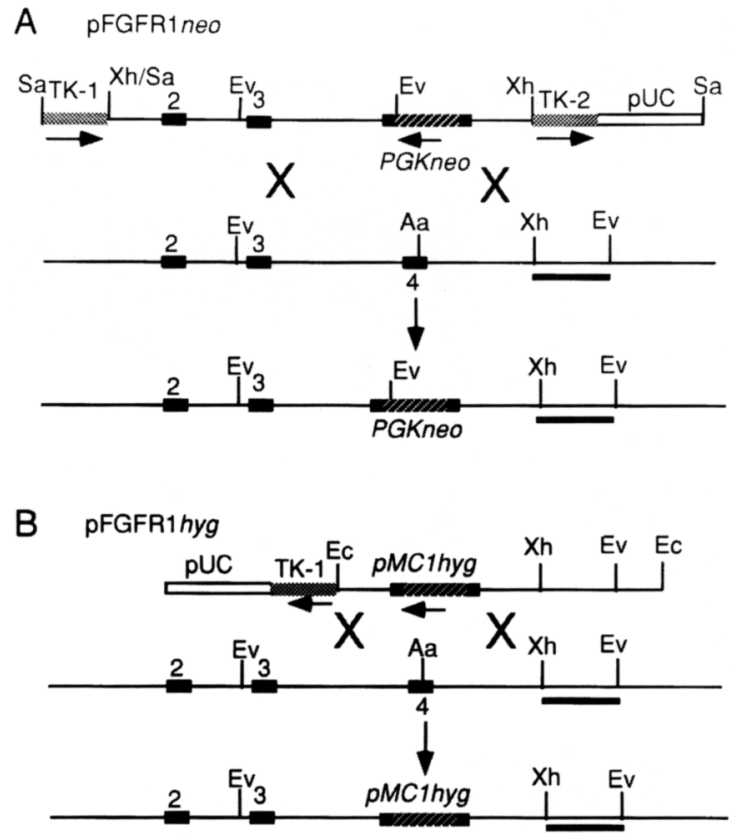

C

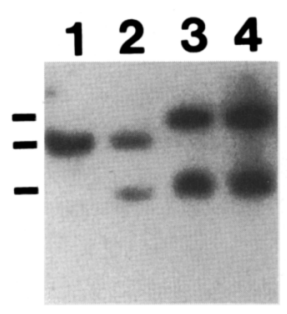


pups. Southern blot analysis indicated that $\sim 50 \%$ of agouti offspring had received the fgfr- $1^{e x 4}$ mutation.

The fgfr- ${ }^{\mathrm{ex} 4}$ mutation results in recessive embryonic lethality

Mice heterozygous for the targeted mutation $\left(f g f r-1^{\text {ex4 }} /\right.$ + | were developmentally and anatomically normal. Twelve of these mice were closely monitored for up to 1 year and were completely normal in terms of growth rate, morphology, health, and fertility (data not shown). When we intercrossed heterozygotes, we found no homozygous fgfr- $1^{\text {ex }}$ mice among 61 newborns analyzed by Southern blotting (Table 1). In subsequent experiments, we have analyzed $>500$ progeny of heterozygote intercrosses without detecting any homozygotes (data not shown). These results indicate that the $f g f r-1^{e \times 4} \mathrm{mu}$ tation is a recessive embryonic lethal.

To determine the timing of fgfr- ex4 $^{\text {ex }}$ homozygous lethality, we dissected embryos from heterozygote intercrosses at different gestational days. From E10.5 to E12.5 (i.e., 10.5 to 12.5 days of gestation), 44 of 61 decidua analyzed contained morphologically normal embryos, whereas the remaining 17 decidua were much smaller in size and contained nearly or completely resorbed embryos (Table 1). In contrast, between E6.5 and E9.5, abnormal embryos were present in some of the smaller decidua, whereas other decidua contained resorptions. After dissecting the abnormal embryos free of maternal tissue, we determined their genotype by polymerase chain reaction (PCR) or Southern blot analysis of DNA extracted from whole embryos or visceral yolk sacs. All normal embryos genotyped were either $+1+$ or fgfr$1^{e \times 4} /+$ at a $1: 2$ ratio, and $92 \%(49 / 53)$ of the abnormal embryos were homozygous for the fgfr- ${ }^{e x 4}$ mutation (Table 1). The remaining abnormal embryos $(8 \%)$ might have been either natural occurrences in this strain background (Table 2) or incorrectly genotyped by PCR because of maternal contamination of the sample. Thus, these data indicate that loss of $f g f r-1$ function results in embryonic lethality during early postimplantation development.

\section{Growth defects observed by in vitro blastocyst culture}

To determine whether preimplantation stages were affected by the targeted mutation, blastocysts were isolated from matings between $f g f_{r}-1^{e \times 4} /+$ mice and were genotyped by PCR either before $(n=10)$ or after in vitro culture $(n=50)$. Wild type, heterozygous, and homozygous blastocysts were recovered in the expected 1:2:1 ratio (Table 1) and appeared morphologically indistinguishable before culture (Fig. 2A,D). These data indicate that embryos homozygous for the targeted mutation are morphologically normal prior to implantation.

However, we observed a dramatic growth disadvantage of homozygous embryos after they were cultured for several days in vitro. During the first 4 days of culture, there were no obvious differences in the morphology of homozygous, heterozygous, and wild-type blastocysts $\langle n=27)$. In this period, cultured blastocysts of all three genotypes formed structures that resembled early egg cylinders. After 5-6 days in culture, however, we observed that the fgfr- 1ex $^{\text {a }}$ homozygous blastocyst outgrowths were consistently smaller than wild-type or heterozygous outgrowths. Specifically, five out of seven $f g f r$ $1^{e x 4}$ homozygous outgrowths (Fig. 2E) were much smaller than the majority of wild-type or heterozygous outgrowths $(13 / 20$; Fig. $2 \mathrm{~B}, \mathrm{C})$, whereas the other two $f g f r-1^{\text {ex }}$ homozygous outgrowths (Fig. $2 \mathrm{~F}$ ) were similar to the remaining seven wild-type or heterozygous outgrowths. Similar observations were made for a second set of embryos ( $n=23$; data not shown). When combined with our in vivo observations of growth retardation in homozygous embryos, as described below, these data are consistent with an early embryonic role for FGFR-1 in stimulating mitogenesis.

Table 1. Morphologies and genotypes of embryos from crosses between fgfr- $\mathrm{e}^{\mathrm{ex} 4} /+$ animals

\begin{tabular}{|c|c|c|c|c|c|c|c|}
\hline Age & $\begin{array}{l}\text { Number of } \\
\text { embryos/litter }\end{array}$ & Normal $^{a}$ & Abnormal & Resorption $^{\mathrm{b}}$ & $1+1+1$ & $\begin{array}{c}\text { Genotype } \\
(1+1-1\end{array}$ & $\mid-1-1$ \\
\hline $\mathrm{E} 3.5^{\mathrm{c}}$ & 60 & $60(60)$ & 0 & 0 & 15 & 31 & 14 \\
\hline E $5.75-6.0^{\mathrm{d}}$ & $47 / 6$ & 45 & 2 & 0 & & & \\
\hline $\mathrm{E} 6.5^{\mathrm{d}}$ & $95 / 11$ & 81 & 12 & 2 & & & \\
\hline E7.5 & $229 / 25$ & $171(21)$ & $32(6)$ & 26 & 6 & 15 & 6 \\
\hline E8.5 & $258 / 27$ & $196(51)$ & $25(11)$ & 37 & 19 & 33 & 10 \\
\hline E9.5 & $423 / 30$ & $297|30|$ & $49(36)$ & 77 & 10 & 23 & 33 \\
\hline E10.5-12.5 & $61 / 7$ & $44(20)$ & 0 & 17 & 6 & 14 & 0 \\
\hline Total (E6.5-12.5) & $1066 / 100$ & 789 & 118 & 159 & & & \\
\hline Newborn-adult & $61 / 9$ & $61 \mid 61)$ & 0 & 0 & 21 & 40 & 0 \\
\hline
\end{tabular}

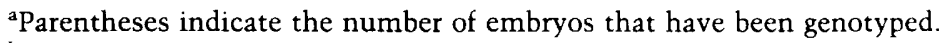

${ }^{b}$ Resorptions were not genotyped because of difficulty in separating embryonic from maternal tissues.

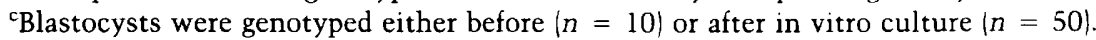

${ }^{\mathrm{d}}$ Embryos were analyzed by sectioning within whole decidua. 
Table 2. Morphologies of embryos generated by mating between wild-type females and heterozygous males

\begin{tabular}{|c|c|c|c|c|c|}
\hline Age & $\begin{array}{l}\text { Number of } \\
\text { litters }\end{array}$ & $\begin{array}{l}\text { Number of } \\
\text { embryos }\end{array}$ & $\begin{array}{l}\text { Normal } \\
\text { embryos }\end{array}$ & $\begin{array}{l}\text { Abnormal } \\
\text { embryos }\end{array}$ & Resorptions \\
\hline E6.0 & 1 & 7 & 7 & 0 & 0 \\
\hline E6.5 & 3 & 30 & 30 & 0 & 0 \\
\hline E7.5 & 8 & 85 & 81 & 2 & 2 \\
\hline E8.5 & 2 & 24 & 19 & 2 & 3 \\
\hline E9.5-E13.5 & 10 & 97 & 96 & 0 & 1 \\
\hline Total & 24 & 243 & 233 & 4 & 6 \\
\hline
\end{tabular}

Developmental delays and resorptions in fgfr $1^{\text {ex4 }}$ embryos are apparent by the onset of gastrulation

To examine the histology of egg cylinder-stage embryos, we fixed and sectioned intact decidual swellings of litters between E5.5 and E6.5 (Table 1). When we analyzed six litters from $f g f r-1^{e \times 4} /+$ intercrosses at $\sim$ E5.75 and E6.0, we found that 45 of 47 embryos appeared morphologically normal. The remaining two embryos were delayed more extensively (not shown), either as a consequence of the targeted mutation or the background rate of resorption (Table 2).

By E6.5, however, we found that $15 \%$ of the decidua (14/95) contained abnormal or partially resorbed embryos (Table 1). The abnormal embryos displayed significant developmental retardation, with shorter egg cylinders and smaller proamniotic cavities than their normal littermates (Fig. 3). Whereas most normal E6.5 embryos had begun to gastrulate, forming a primitive streak and posterior amniotic fold (Fig. 3C), the developmentally delayed embryos had not yet begun to gastrulate (Fig. $3 \mathrm{D}, \mathrm{E})$. Although we have been unable to genotype these embryos because of their size, it is likely that they are fgfr- $1^{\text {ex }} 4$ homozygotes, because growth retardation was not observed in control crosses between wild-type females and fgfr-1ex4/ + males (Table 2). These observations suggest that a significant portion of $f g f r-1^{e x 4} \mathrm{em}$ - bryos display a growth defect by the onset of gastrulation.

From E6.5 onward, a high frequency of resorption in the litters of heterozygous crosses was readily observed (Table 1). Most resorption sites found in earlier stages of gastrulation (E6.5 and E7.5) contained partially resorbed embryos (Fig. 3A), whereas $>50 \%$ of later resorption sites (E8.5 and E9.5) contained completely resorbed embryos (Figure 3B). Because little or no embryonic tissue could be recovered from these resorption sites, we could not genotype them reliably by Southern blotting or by PCR. However, the sum of abnormal embryos and resorptions from E6.5 to E12.5 $(n=277)$ was approximately one-quarter of the total embryos analyzed at these stages $(n=1066)$, indicating that the resorptions represent one of the phenotypes of FGFR-1 deficiency. As a control for the effect of the mixed genetic background, we determined that the rate of abnormal embryos plus resorptions was $4 \%$ in crosses between $f g f r-1^{\text {ex }} 4 /+$ males and wild-type female littermates (Table 2). These results suggest that the vast majority of resorptions found in matings between $f g f r-1^{e x 4} /+$ mice represent homozygous mutant embryos.

\section{Phenotypic variability during gastrulation}

Although a significant number of presumptive $f g f r-1^{\text {ex4 }}$

Figure 2. Culture of blastocysts in vitro. Blastocysts and blastocyst outgrowths shown in $A-C$ are either wild type or heterozygous for the $f_{g} f_{\mathrm{r}-\mathrm{I}^{\mathrm{ex}}}$ mutation, whereas those shown in D-F are homozygotes. $(A, D)$ Blastocysts prior to in vitro culture; outgrowths shown in $B, C, E$, and $F$ have been cultured for 5 days in vitro. $(B, C)$ Representative examples of blastocyst outgrowths that are wild type or heterozygous for the $f g f r-1^{e x 4}$ mutation. $(E)$ A representative homozygous blastocyst outgrowth; $(F)$ the largest homozygous outgrowth obtained. Bar, $8.4 \mu \mathrm{m}$ in $A$ and $D ; 17 \mu \mathrm{m}$ in $B, C$, $E$, and $F$.
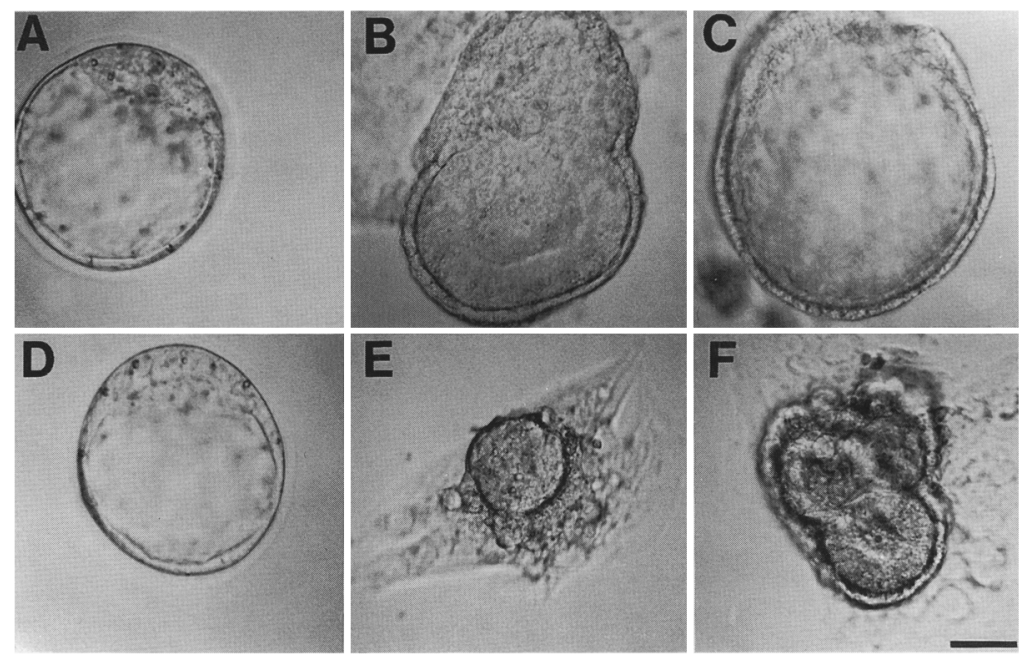


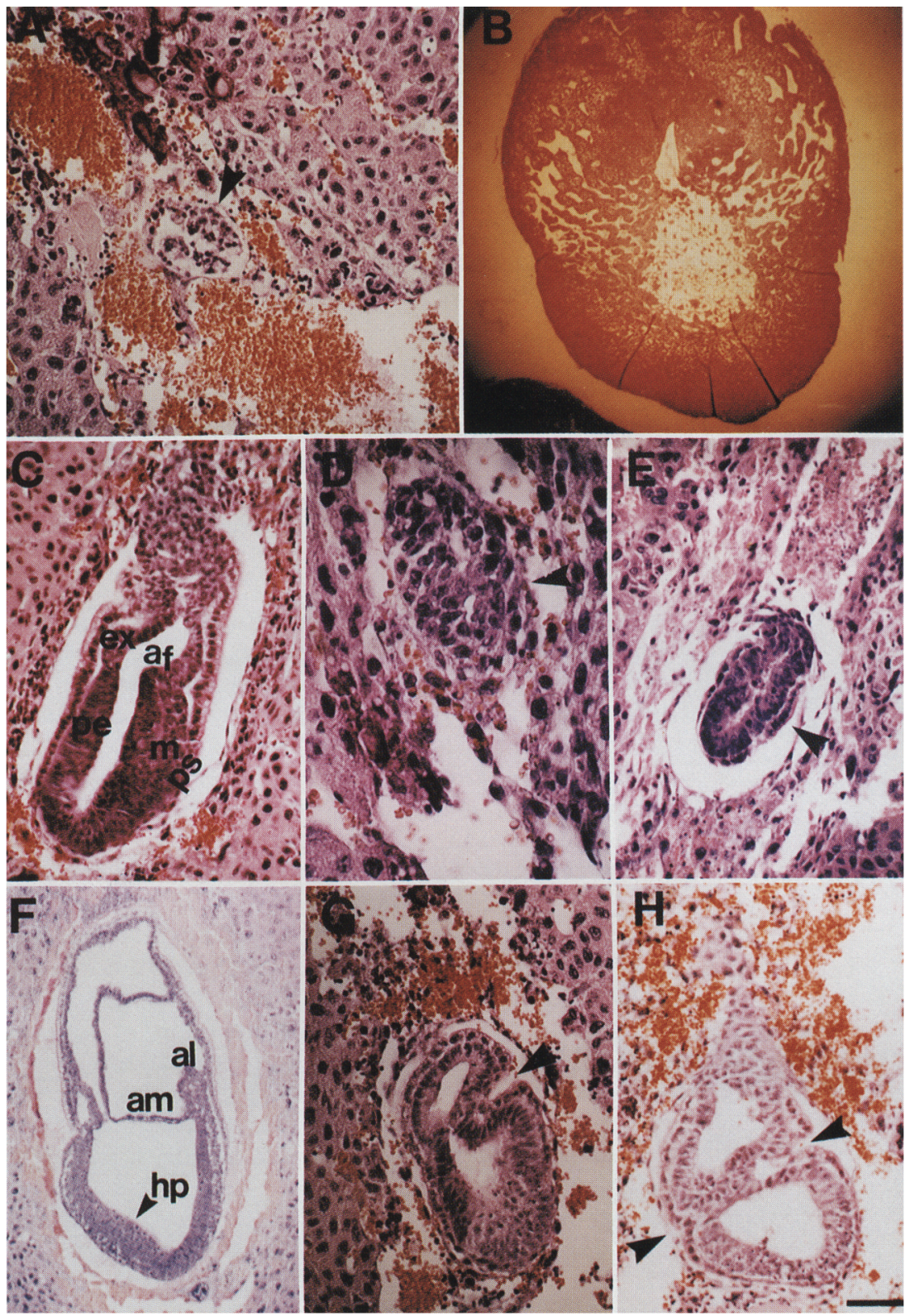

Figure 3. Histological sections of embryos generated by crosses between fgfr- ex4 $^{e+}+$ mice. $(A)$ Partially resorbed E7.5 embryo (arrowhead). (B) Completely resorbed E9.5 embryo. (C) Sagittal section of a wild-type E6.5 embryo, showing a primitive streak extended up to $\sim 70 \%$ of the length of the posterior side. $(D)$ Partially lysed E6.5 embryo (arrowhead). (E) Developmentally retarded E6.5 embryo (arrowhead). (F) Sagittal section of a late streak-stage (E7.5) embryo. $(G, H)$ Developmentally delayed embryos that are generally between $10 \%$ and $50 \%$ of normal length. An unusually prominent invagination at the circumferential constriction (indicated by arrowheads) is so deep that embryos resemble the figure " 8 ". (af) Amniotic fold; $\{\mathrm{am}$ | amnion; (al) allantois; (ex) extraembryonic ectoderm; (hp) head process; (m) mesoderm; (n) node; (pe) primitive ectoderm; (ps) primitive steak. Bar, $18 \mu \mathrm{m}$ in $A$, $C, E, G$, and $H ; 140 \mu \mathrm{m}$ in $B ; 8.8 \mu \mathrm{m}$ in $D ; 35$ $\mu \mathrm{m}$ in $F$. homozygotes were resorbed before gastrulation, many mutant embryos survived after E6.5 and were recovered as late as E9.5. At E7.5, most normal embryos $(n=171)$ were at the late primitive streak stage and some had advanced further (Fig. 3F). In contrast, all abnormal embryos $(n=32)$ were growth retarded, with some displaying an unusually prominent invagination at the circumferential constriction that divides the egg cylinder between embryonic and extraembryonic ectoderm (Fig. $3 \mathrm{G}, \mathrm{H})$.

At E8.5, the ratio of resorptions to abnormal embryos increased, indicating that more fgfr- $1^{e x^{4}}$ homozygotes were dying (Table 1). Some of these mutants were extremely small, resembling those found in E7.5 litters (Fig. 4B). Other homozygotes had an extraembryonic por- tion that was significantly larger than their embryonic portion, so that they resembled a "comma" (Fig. 4A). These mutants displayed little identifiable mesodermal differentiation and represented the majority of abnormal embryos found at E8.5. Histological sections demonstrated that these embryos had abnormally thickened primitive streak regions, with limited outgrowth of extraembryonic mesoderm (Fig. 5B,C).

Significant phenotypic diversity was observed in $f g f r-$ $1^{\text {ex4 }}$ homozygotes isolated from E9.5 litters. Approximately two-thirds of mutant embryos seemed to be derived from the growth of comma-shaped embryos, having formed an abnormal visceral yolk sac that was significantly larger than the embryonic portion (Fig. 4E). These embryos often appeared to have very little poste- 

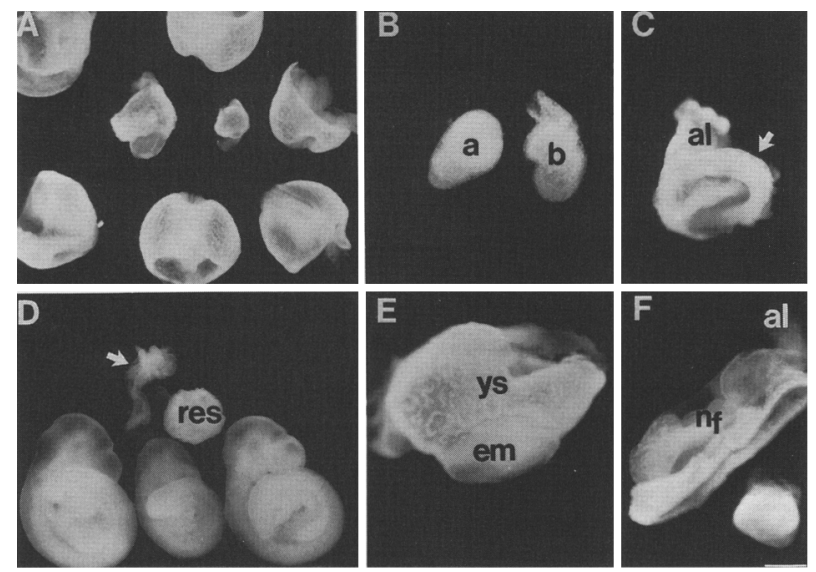

Figure 4. Phenotypic variability of $f g f r-1^{e x 4}$ homozygotes. $(A-$ $C)$ E8.5 embryos; $(D-F)$ E9.5 embryos. All abnormal embryos have been genotyped and are $f_{g} f_{r}-1^{e x 4}$ homozygotes. (A) Embryos isolated from a single litter generated by a fgfr-1 $1^{\text {ex4 }} /+$ intercross. Two comma-like embryos in the center are surrounded by six normal embryos that are either wild-type or heterozygous littermates. $(B)$ Egg cylinder $(a)$ and figure $8(b)$ embryos. $(C)$ An embryo with abnormal neural fold-like structures (arrow) directly attached to the allantois. (D) An abnormal embryo (arrow), a complete resorption, and three normal littermates. $(E)$ An embryo with a yolk sac that is enlarged relative to the embryonic portion. $(F)$ An embryo with missing trunk and tail regions. (al) Allantois; (em) embryonic portion of the embryo; (nf) neural fold; (res) resorption; (ys) yolk sac. Bar, $22 \mu \mathrm{m}$ in $A$ and $D ; 3.6 \mu \mathrm{m}$ in $B ; 11 \mu \mathrm{m}$ in $C, E$, and $F$.

rior extension of the embryonic axis, so that anterior neural fold-like structures were connected to a relatively normal allantois (Fig. 4C). Other abnormal embryos had little or no axial organization and resembled a flattened disk (not shown). Finally, the most advanced E9.5 mutant embryos were significantly larger than most $f g f r$. $1^{e x 4}$ embryos but were still much smaller than their normal littermates. These mutants seemed to have defined trunk and tail regions, but these structures were highly abnormal when compared with wild-type littermates (Fig. 4D).

\section{Nonaxial mesoderm differentiation in homozygous embryos}

In general, we found that homozygous $f g f r-1^{e x 4}$ embryos were capable of forming nonaxial mesodermal tissues such as allantois, amnion, visceral yolk sac mesoderm, and blood. The allantois of $f g f r-1^{e x 4}$ homozygotes was usually well-formed, although sometimes exaggerated in size (Fig. 5E,F,H). In contrast, we observed that the visceral yolk sac of $f g f r-1^{e x 4}$ homozygotes was always significantly smaller and abnormal. The surface of the visceral yolk sac of fgfr-1 ${ }^{\text {ex }} 4$ homozygotes was noticeably bumpy and formed characteristic "ruffled" structures. This visceral yolk sac ruffling may be a consequence of underproliferation of the inner layer of extraembryonic mesoderm with respect to the outer layer of visceral en- doderm (Fig. 5H). Despite the limited growth of yolk sac mesoderm, however, some E9.5 fgfr- $1^{\text {ex4 }}$ homozygotes formed blood islands and circulating nucleated erythrocytes (Fig. 5I). One of the most advanced fgfr- $1^{\text {ex4 }}$ homozygotes possessed an abnormal heart with internal blood cells (Fig. 5G).

In addition to formation of nonaxial mesodermal tissues, $f g f r-1^{\text {ex }}$ homozygotes also displayed some morphological differentiation of the head. Thus, by E9.5, the most advanced $f g f r-1^{e x 4}$ homozygotes possessed structures that resemble head folds prior to anterior neuropore closure (data not shown). These headfolds were never normal in size or morphology (Fig. 5H), compared with normal embryos (Fig. 5A,D). Other anterior structures that have been occasionally observed include apparent otocysts and branchial arches (not shown).

\section{Disorganized axial structures in homozygous embryos}

In contrast to the relative ability of $f g f r-1^{\text {exa }}$ homozygotes to form head structures and nonaxial mesodermal tissues, we observed significant defects in their ability to differentiate and organize axial and paraxial structures of the trunk and tail (Figs. 4C and F; 5F and G). Even in the most advanced $f g f r-1^{e x 4}$ embryos that have an apparent anterior-posterior axis, the posterior trunk regions were frequently disorganized and displayed folding of ectodermal layers, again suggesting mismatched growth rates of cell layers (Fig. 5G,H). Most notably, we have never observed proper differentiation of a neural tube, formation of overt somites, or signs of limb bud formation.

To further characterize these defects in axial organization, we employed whole-mount in situ hybridization to examine two markers for midline structures. First, we used a riboprobe from the Brachyury gene to examine primitive streak and notochord differentiation in $f g f r$ $1^{e x 4}$ homozygotes $(n=8)$. At E7.5, Brachyury is normally expressed in the primitive streak, node, and head process, and at E8.5 and E9.5 it is observed in the tail bud and notochord (Wilkinson et al. 1990; Herrmann 1991) [Fig. 6A (left), B,C]. In fgfr-1 ${ }^{\text {ex4 }}$ homozygotes, only a patch of staining was evident at E7.5 (Fig. 6A, right), whereas a thicker band of staining was commonly found at E8.5 (Fig. 6D), consistent with the abnormally thickened primitive streak region observed in histological sections (Fig. $5 \mathrm{C}$ ). At E9.5, fgfr- $1^{\text {exd }}$ homozygotes that lacked overt axial organization (flattened disks) often displayed large patches of disorganized Brachyury expression (Fig. 6E). Homozygotes possessing an overt anterior-posterior axis often showed an excess of midline Brachyury staining (Fig. 6F), presumably corresponding to streak- or notochord-like structures.

These defects in midline structures were confirmed by using a riboprobe from the Sonic hedgehog (Shh) gene, which is normally expressed in the notochord, floor plate, foregut, hindgut, and ventral diencephalon at E8.5 and E9.5 (Fig. 6G, H; Echelard et al. 1993). At E9.5, fgfr$1^{e x 4}$ homozygotes $(n=5)$ displayed profound abnormalities in presumptive notochordal staining [Fig. 6I,J (arrowhead)], again demonstrating defective axial organization. 

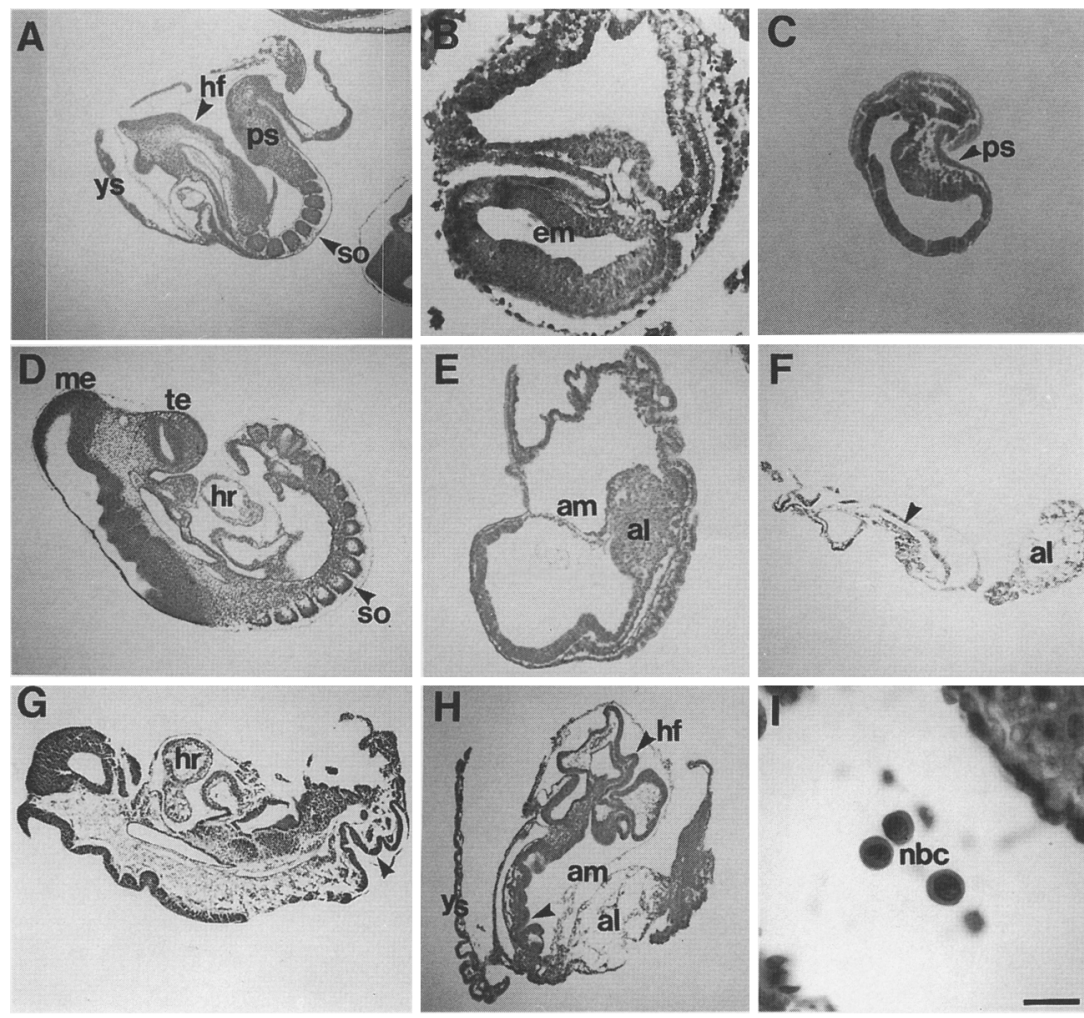

Figure 5. Histological sections of embryos at E8.5 and E9.5. $(A-C)$ E8.5 embryos; $(D-H)$ E9.5 embryos. $(A, D) f g f r-1{ }^{\text {ex4 }} /+$ heterozygotes; all other panels show fgfr- $1^{\text {ex }} 4$ homozygotes. (I) Nucleated embryonic blood cells (nbc) from the heart of a E9.5 fgfr- ${ }^{\text {ex }} 4$ homozygote. The arrowhead in $F$ indicates an abnormal neural plate. Arrowheads in $G$ and $H$ indicate regions of apparent ectodermal folding. (al) Allantois; (am\} amnion; (em) embryonic portion of embryo; (hf) head fold; (hr) heart; (me) mesencephalon; (ps) primitive streak; (so) somites; (te) telencephalon; (ys) yolk sac. Bar, $70 \mu \mathrm{m}$ in $A, D, E, G$, and $H ; 18 \mu \mathrm{m}$ in $B$ and $C ; 55 \mu \mathrm{m}$ in $F ; 3.5 \mu \mathrm{m}$ in $I$.
As with the Brachyury probe, we frequently observed expanded bands of midline staining, suggesting an excess of presumptive axial mesoderm (Fig. 6K,L). Whereas all homozygous embryos analyzed displayed some Shh expression, we never found structures that resembled normal notochord or floor plate. These observations suggest that $f g f r-1^{e x 4}$ homozygotes are able to differentiate cells with primitive streak- and notochord-like characteristics, albeit in a severely disorganized fashion.

\section{FGFR-1-deficient ES lines can differentiate normally into mesodermal cell types}

One conceivable explanation for the lack of somite formation and other mesodermal defects in $f g f r-1^{e x 4}$ homozygotes is that these abnormalities are attributable to intrinsic blocks in mesodermal differentiation pathways. To determine whether this is the case, we tested whether ES cells lacking FGFR-1 can differentiate normally into a variety of mesodermal cell types. For this purpose, we have generated ES cell lines with two disrupted $f_{g} f \mathrm{r}-1$ alleles by targeting the wild-type allele in heterozygous ES cells $\left(f g f r-1^{e \times 4} /+\right)$ with the construct pFGFR 1 hyg (Fig. 1B). The fgfr- $1^{e x 4} / f_{g} f_{r}-1^{e x 4 h}$ ES cell lines generated by this targeting experiment are morphologically indistinguishable and have similar growth rates in vitro compared with the parental $f g f r-1^{\text {ex4}} /+$ line (not shown).

We have tested the ability of these ES cell lines to differentiate in vivo by generating teratomas through subcutaneous injection into nude mice. Regardless of their genotypes, $f g f_{r}-1^{e x 4} / f g f_{r}-1^{e x 4 h}, f g f r-1^{e x 4} /+$, and wild-type ES cells formed tumor masses that were visible between 1 and 2 weeks following injection, becoming $1-2 \mathrm{~cm}$ in diameter after $3-4$ weeks. Histological examination indicated that teratomas formed from these cells consisted of many different cell types, including squamous and glandular epithelium, neurons, and cartilage (data not shown). In particular, the $f g f r-1^{e \times 4} / f g f r-1^{e x 4 h}$ ES cells could form muscle cells that are histologically indistinguishable from those formed by the $f g f r-1^{e x 4} /+$ ES cells (Fig. 7). We therefore conclude that disruption of $f g f r-1$ is unlikely to result in a significant intrinsic defect in the differentiation of many mesodermal cell types. Instead, the mesodermal defects found in $f g f r-f^{e x 4}$ homozygous embryos are probably an indirect consequence of abnormal pattern formation.

\section{Discussion}

\section{Distinct requirements for FGFR-1 in early embryonic development}

We have observed phenotypic defects in $f_{g} f_{-}-1^{e x 4}$ homozygotes in many tissues and cell types that are known to express FGFR-1. In wild-type embryos, transcripts for fgfr-1 are first detectable at the blastocyst stage /Campbell et al. 1992), and are then found in the primitive ectoderm of the egg cylinder and in migrating embryonic mesoderm during gastrulation (Orr-Urtreger et al. 1991). Later, starting with somitogenesis, $f g f r-1$ is actively transcribed in both the mesoderm and neuroectoderm /Ya- 
Deng et al.

Figure 6. Whole-mount in situ hybridization of wild-type and $f g f_{r}-1^{e \times 4}$ homozygous embryos. $(A-F)$ Hybridization with a Brachyury riboprobe. (A) Wild-type and fgfr- $1^{\text {ex } 4}$ homozygous E7.5 embryos. $(B)$ Wild-type E8.5 embryo. (C) Wild-type E9.5 embryo (dark field). (D) fgfr- $1^{e x 4}$ homozygous E8.5 embryo. (E) fgfr-1 ex $^{4}$ homozygous E9.5 embryo lacking well-defined anterior-posterior axis, showing large patches of scattered staining. $(F)$ fgfr- $1^{\text {ex4 }}$ homozygous E9.5 embryo with diffuse broad midline staining. $(G-L)$ Hybridization with a Sonic hedgehog riboprobe. $(G)$ Wild-type E8.5 embryo; $(H)$ wild-type E9.5

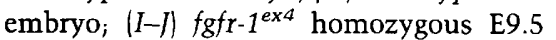
embryos. In $I$, positive staining is indicated by the arrowhead. In $L$, note the diffuse midline staining of the presumptive notochord (arrow), which resembles the Brachyury staining in $F$. The arrowhead in $L$ points to presumptive hindgut staining. (al) Allantois; (di) diencephalon; (hi) hindgut; (nt) notochord; (ps) primitive streak; (tb) tailbud; (ys) yolk sac. Bar, $35 \mu \mathrm{m}$ in $A$ and $G ; 30 \mu \mathrm{m}$ in $B, F, l$, and $L ; 65 \mu \mathrm{m}$ in $C$ and $H ; 20 \mu \mathrm{m}$ in $D$ and $K ; 25 \mu \mathrm{m}$ in $E$ and $I$.

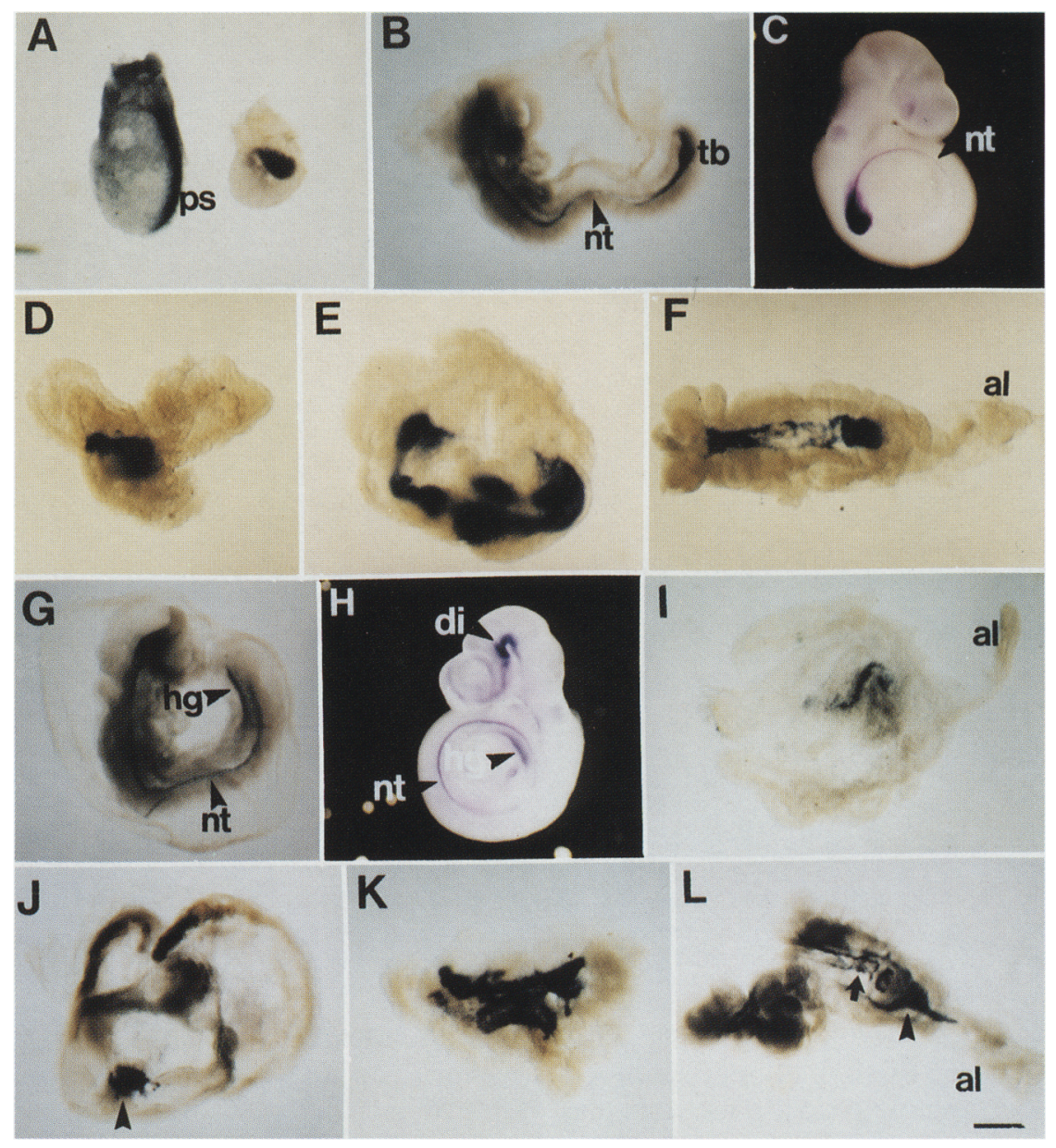

maguchi et al. 1992). This expression pattern is consistent with observed defects of $f g f r-1^{e x 4}$ homozygotes in the proliferation of primitive ectoderm and differentiation of embryonic mesoderm.

Somewhat surprisingly, however, our analysis suggests that FGFR-1 is required for two distinct functions in early embryogenesis. First, the appearance of resorptions and growth retardation by the onset of gastrulation indicates that the earliest deaths of $f g f r-1^{\text {ex4 }}$ homozygotes are not a consequence of defects in mesoderm differentiation or patterning. Instead, we believe that these early abnormalities result from insufficient responses to mitogenic stimuli, because of disruption of the FGF signaling pathway. Consistent with this view, all fgfr-1 ${ }^{\text {ex4 }}$ homozygotes recovered at later embryonic stages display severe developmental delays and growth deficiencies. Notably, we find that the requirement for fgfr-1 in cell proliferation appears greater in embryonic tissues, consistent with the observed expression pattern of the gene (Yamaguchi et al. 1992). Cell proliferation may be most dependent on FGFR-1 in mesodermal tissues, as suggested by the folding or ruffling of nonmesodermal cell layers in the head and visceral yolk sac of $f g f_{r}-1^{e \times 4}$ homozygotes. Furthermore, $f g f r-1^{e \times 4}$ blastocyst outgrowths demonstrate noticeable growth retardation after several days of in vitro culture. This observation strongly argues that the growth abnormalities of $f g f r-1^{e x 4}$ embryos in

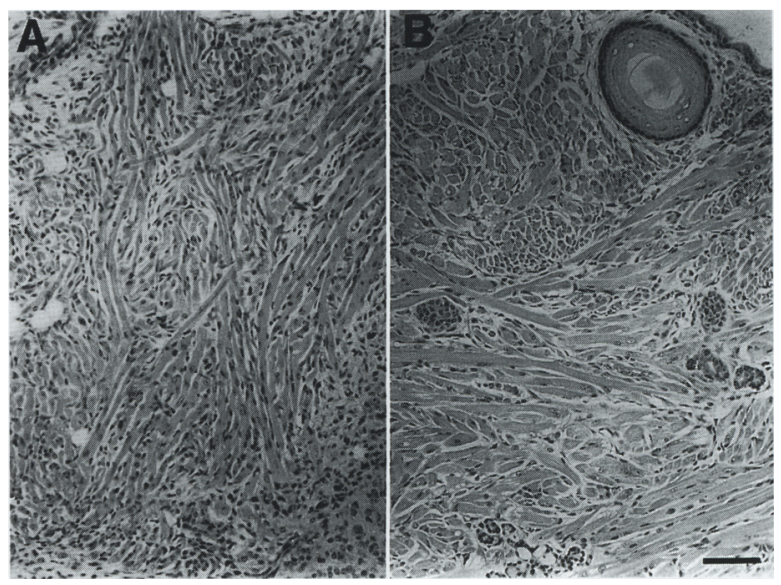

Figure 7. Histological sections of teratomas derived from $f f_{\mathrm{r}^{-}}$$1^{\text {ex4 }} /+$ and $f g f_{r}-1^{\text {ex4 }} / f g f_{r}-1^{\text {ex4h }}$ ES cells. Shown are muscle cells obtained from injection of $11-22$, an $f g f_{r-1}{ }^{e x 4} /+$ ES cell line $(A)$, and from injection of $23-46$, an $f g f_{r}-1^{\text {ex4 }} / f g f_{I}-1^{\text {exth }}$ ES cell line (B). Bar, $18 \mu \mathrm{m}$. 
vivo represent intrinsic defects and are unlikely to result from blocks in maternal-embryonic interactions. Our results therefore indicate that FGFR-1 is required for transmitting important mitogenic stimuli in early embryogenesis.

FGFR-1-deficient embryos have extensive abnormalities in both axial and paraxial structures such as the primitive streak, notochord, head folds, and somites, as demonstrated by histological analysis and by wholemount in situ hybridization. In principle, some of these abnormalities may simply represent a consequence of early growth defects of specific cell types or structures that are essential for axial organization. If this is the case, FGFR-1 might function solely as a mediator of mitogenic stimuli and would not be directly involved in differentiation or pattern formation. However, it is difficult to see how defects in cell proliferation could account for phenotypes such as the accumulation of cells in the primitive streak and the expansion of axial mesoderm.

Alternatively, FGFR-1 may have an additional function distinct from promoting cell proliferation, such as specifying mesodermal differentiation and/or patterning. Because differentiation of FGFR-1-deficient ES cell lines proceeds normally in teratomas, it is unlikely that FGFR-1-deficient cells possess intrinsic blocks in mesodermal differentiation pathways. Instead, defects in the allocation of progenitor cells among alternative pathways of mesoderm differentiation are more consistent with the phenotypes of FGFR-1-deficient embryos. Thus, one of the earliest phenotypes observed was the formation of an abnormal primitive streak region, as shown by the prominent invagination and by the accumulation of cells in the streak (Fig. 5C). It is known that different mesoderm subpopulations are derived from cells migrating from different regions of the primitive streak (Tam 1989; Lawson et al. 1991; Lawson and Pedersen 1992). Abnormalities in the primitive streak region might cause alterations in migration patterns or pathways of primitive cells, which, in turn, change cell fate and severely affect subsequent mesoderm formation and differentiation. For example, the expansion of the presumptive axial mesoderm at the expense of the paraxial mesoderm could be caused by a lateral migration failure of cells at the anterior end of the streak. This would be consistent with the observed increase in midline expression of Brachyury and Shh, and with the reduction of yolk sac mesoderm and failure to form somites. Thus, in the absence of FGFR-1, the proper allocation of mesodermal progenitors among different embryonic regions and/ or differentiation pathways may be disrupted. Such defects in cell fate allocation might be analogous to the formation of neuroectoderm in Xenopus embryos blocked in activin receptor signaling (Hemmati-Brivanlou and Melton 1992, 1994).

\section{Phenotypic variation and functional redundancy of FGF receptors}

Interestingly, we have observed a significant variation in the phenotype of $f g f r-1^{e x 4}$ homozygotes, which can be accounted for by several possible explanations. First, this phenotypic variation might arise through functional redundancy of FGFR-1 with other members of the FGF receptor family. In vitro binding studies have demonstrated that each receptor gene can produce protein products that can bind to several FGF ligands, with differing binding specificities generated through alternative splicing (Dionne et al. 1990; Mansukhani et al. 1990; Dell and Williams 1992; Duan et al. 1992; Ornitz and Leder 1992; Vainikka et al. 1992; Werner et al. 1992; Ron et al. 1993). For example, all four fgfr genes can express receptors that bind to aFGF with high affinities while binding bFGF and $k F G F$ with varying affinities. Thus, phenotypic variation may result from lower ligand binding affinities of redundant FGFRs, increasing their sensitivity to threshold signaling effects that may be influenced by epigenetic phenomena.

Second, phenotypic variation may be a consequence of a nonuniform genetic background (129/terSV $\times$ NIH Black Swiss\}, resulting in segregation of potential modifying loci. Our preliminary results show that the resorption rate from crosses between $f_{f r-1}{ }^{e x 4} /+$ mice increases slightly (to $5 \%$ ) in the inbred $129 /$ terSV background. However, abnormal embryos resembling those in Figures 3, 4, and 5 have also resulted from these crosses (C-X. Deng and M.M. Shen, unpubl.). These findings suggest that a mixed genetic background cannot be completely responsible for the phenotypic variation in fgfr- $1^{\text {ex }}{ }^{4}$ homozygotes.

Finally, phenotypic variation might be attributable to the expression of a severely truncated gene product. However, the fgfr- $-{ }^{e \times 4}$ mutation severely truncates all known FGFR-1 isoforms, except for a single isoform that only possesses an Igl domain (Eisemann et al. 1991), which is poorly characterized. It is also conceivable that any potential truncated FGFR-1 products might act in a dominant-negative fashion, perhaps through competition for ligand binding with FGFR-1 or other FGFRs. However, in vitro assays demonstrate that both the Ig2 and Ig3 domains are required for high-affinity ligand binding (Zimmer et al. 1993), whereas the presence or absence of the Igl domain has very little effect (Miki et al. 1992). Therefore, we believe our $f g f r-1^{e x 4}$ disruption is a strong reduction or loss-of-function mutation and represents a candidate null mutation. This conclusion is supported by studies from the accompanying paper in which Yamaguchi and Rossant (this issue) have generated a mouse strain with a similar phenotype by deleting the transmemberane and a part of the catalytic domain of the fgfr-1 gene.

\section{The FGF signaling pathway and mesoderm formation in mouse and frog}

Many experiments on Xenopus embryos have supported a role for the FGF signaling pathway in mesoderm induction. Injection of a dominant-negative FGFR construct into intact embryos frequently results in tadpole- 
stage animals displaying nearly complete head differentiation, but lacking trunk and tail structures, indicating that FGF signaling is involved in specifying the differentiation of ventral and posterior mesoderm in Xenopus (Amaya et al. 1991, 1993). Further analysis has demonstrated that dominant-negative FGFRs can inhibit the differentiation of more dorsal mesoderm both in intact Xenopus embryos and in activin-treated animal caps. Specifically, dominant-negative FGF receptors can block the expression of Brachyury and other markers of nonprechordal mesoderm, including those for skeletal muscle (Amaya et al. 1993; Cornell and Kimelman 1994; LaBonne and Whitman 1994).

To some extent, the phenotypes of $f g f_{r}-1^{e x 4}$ homozygotes resemble those of Xenopus embryos that have been injected with dominant-negative FGFR constructs. In particular, similar pattern truncations are found in some fgfr- $1^{\text {ex }}$ homozygotes in which head fold-like structures are juxtaposed to the allantois. However, unlike these Xenopus embryos, $f g f_{r}-1^{e x 4}$ homozygotes possess significantly abnormal head structures. In addition, $f g f r-1^{e x 4}$ homozygotes can form many extraembryonic mesodermal cell types, such as allantois, amnion, yolk sac mesoderm, and blood, which are derived from "posterior" primitive streak regions in the fate map of the gastrulation-stage mouse embryo (Lawson et al. 1991).

Most notably, however, FGFR-1 is not absolutely required for mesoderm formation in the mouse. For example, FGFR-1 is not required for Brachyury expression, as demonstrated by whole-mount in situ analysis. Murine FGFR-1 is also not required for the differentiation of muscle or other mesodermal cell types, as shown by the analysis of FGFR-1-deficient ES cells. Thus, the failure to form somitic mesoderm in FGFR-1-deficient mice is likely to be a consequence of defective mesodermal pattern formation. The basis for these phenotypic differences between mouse and frog may reflect species differences in receptor redundancy or signaling pathways. Alternatively, the potentially broader action of a dominantnegative construct on the entire FGF receptor family may differ from the effects of a specific disruption of FGFR-1 function.

Our analysis indicates that FGFR-1 is required during mouse embryogenesis for two essential functions: proper embryonic cell proliferation and pattern formation. Although the patterning abnormalities in FGFR-1-deficient mice might be caused either by a mitogenic defect, or by a defect occurring at earlier stages of the gastrulation process, a dual role for FGFR-1 is consistent with biochemical analyses of an FGFR with a point mutation in its cytoplasmic domain at the autophosphorylation site Tyr-766 (Mohammadi et al. 1992; Peters et al. 1992). This mutated receptor is defective for phospholipase $\mathrm{C} \gamma$ signaling and phosphatidylinositol hydrolysis but is still able to mediate mitogenic activity in transfected myoblasts. Interestingly, it has been proposed that a high rate of phosphatidylinositol turnover is involved in specifying ventral mesoderm in frog embryogenesis (Berridge et al. 1989). It is therefore conceivable that FGFR-1 could utilize distinct signal-transducing domains to mediate cell proliferation and axial patterning in mouse development.

\section{Materials and methods}

\section{Targeting vectors}

Recombinant phages containing genomic DNA of $f g f_{r}-1$ were isolated from a 129 mouse library (Stratagene) by using a mouse $f g f_{r}-1 \mathrm{cDNA}$ probe. Two overlapping fragments containing exon 4, a 9-kb XhoI-SalI fragment (the SalI site is from the polylinker region of the $\lambda$ Fix II phage vector) and a $6-\mathrm{kb}$ EcoRI fragment, were subcloned into pBluescript IIKS(+) (Stratagene). To make the pFGFR lneo targeting vector, we inserted the PGKneo gene (Tybulewicz et al. 1991) into exon 4 of fgfr-1 at a unique AatII site in the 9-kb Xhol-Sall fragment. Two different thymidine kinase genes, $T K-1$ and $T K-2$ (Mansour et al. 1988; Thomas and Capecchi 1990|, were then placed at the $5^{\prime}$ and $3^{\prime}$ ends of the genomic DNA, respectively (Fig. 1A). The pFGFR1hyg vector was constructed by inserting a pMClhyg gene (provided by $\mathrm{Dr}$. Teruhisa Tsuzuki, Kyushu University, Japan) into the fourth exon in the 6-kb EcoRI fragment followed by the addition of TK-1 at the $5^{\prime}$ end of the genomic DNA (Fig. 1B). Both targeting vectors were partially sequenced to confirm the predicted insertions of neo and hyg genes (data not shown).

\section{Homologous recombination in ES cells}

The culture, electroporation, and selection of $\mathrm{Jl}$ cells was carried out as described (Li et al. 1992). ES cell colonies that were resistant to both G418 and FIAU were analyzed by Southern blotting for homologous recombination events. Genomic DNA from these cell lines and the parental cell line was digested with EcoRV and probed with a 2-kb 3 '-flanking fragment specific for the fgfr- 1 locus. DNA from the parental ES lines showed a 9-kb fragment diagnostic of the wild-type $f g f r-1$ gene, but in targeted cell lines this fragment was shifted down to $6 \mathrm{~kb}$ as the result of the introduction of an EcoRV site in PGKneo (Fig. 1C, lanes 1,2). Correct targeting was confirmed by digestion with other enzymes (BamHI and EcoRI), and by using internal probes (data not shown). Of a total of $60 \mathrm{G} 418^{\mathrm{r}}$ FLAU $^{\mathrm{r}}$ colonies analyzed, 19 contained the targeted fgfr- $1^{\text {ex } 4}$ disruption. In absolute terms, the targeting frequency achieved by the pFGFR1 neo vector was one event per $2 \times 10^{5}$ electroporated ES cells.

The transfection conditions of pFGFRlhyg were identical to those of pFGFR Ineo. After electroporation, ES cells were plated on a layer of hygromycin-resistant feeder cells (provided by Dr. Mario Capecchi, University of Utah, Salt Lake City) and selected with hygromycin B at a concentration of $100 \mu \mathrm{g} / \mathrm{ml}$. ES cells resistant to both hygromycin and FIAU were analyzed for homologous recombination events by Southern blotting with the same probe used in the first round of targeting. Among 90 hyg $^{\mathrm{r}}$-FIAU ${ }^{\mathrm{x}}$ clones analyzed, 2 showed the expected band shift, indicating that the wild-type allele was disrupted (Fig. 1C, lanes $3,4)$. Additional analysis using multiple enzyme digestions confirmed that the targeting events in these $f g f_{r}-1^{\text {ex4 }} / f_{g} f_{r}-1^{\text {ex } 4 h}$ clones were accurate. These clones contained no wild-type $f_{g} f_{r}-1$ message as assayed by reverse transcriptase (RT)-PCR, using primers spanning the neo insertion site, whereas transcripts in the parental 11-22 ES cell line were readily detectable (data not shown).

\section{Generation of germ-line chimeras}

We superovulated 4-week-old $\mathrm{C} 57 \mathrm{Bl} / 6 \mathrm{~J}$ females with $2.5 \mu$ of pregnant mare's serum (Calbiochem) 2 days prior to mating and 
with $2.5 \mu$ hCG (Organon) on the day of mating with C57Bl/6J males. Blastocysts were collected from pregnant $\mathrm{C} 57 \mathrm{Bl} / 6 \mathrm{~J}$ females at 3.5 days postcoitum. Approximately 15-18 ES cells were microinjected into each blastocyst. The injected blastocysts were implanted into the uteri of pseudopregnant Swiss Webster (Taconic) foster mothers and allowed to develop to term. Male chimeras (identified by the presence of agouti coat color) were test mated with NIH Black Swiss females (Taconic). These animals were used for testing for germ-line transmission because they have larger litters and care for their offspring better than $\mathrm{C} 57 \mathrm{Bl} / 6 \mathrm{~J}$ females (data not shown). Germ-line transmission was confirmed by agouti coat color in the $F_{1}$ animals, and all agouti offspring were tested for the presence of the fgfr-1 ex4 $^{\text {ex }}$ allele by Southern analysis or PCR.

\section{Genotype analysis}

For adults and embryos of 8.5 days of gestation and older, we determined most genotypes by Southern blotting using the flanking probe described above. For embryos younger than E8.5, we determined genotypes by PCR. For PCR analysis, embryos or visceral yolk sacs were incubated in $200 \mu$ l of extraction buffer $50 \mathrm{~mm}$ Tris-Cl at $\mathrm{pH} 8.0,100 \mathrm{~mm}$ EDTA, $1 \%$ SDS, $100 \mu \mathrm{g} / \mathrm{ml}$ proteinase $\mathrm{K}$ ) for $1 \mathrm{hr}$ at $50^{\circ} \mathrm{C}$. After digestion, samples were extracted once with an equal volume of phenol/chloroform and once with an equal volume of chloroform/isoamyl alcohol (49: 1). DNA was precipitated with two volumes of $100 \%$ ethanol, together with $10 \mu \mathrm{g}$ of yeast tRNA as a carrier, and then dissolved in 20-50 $\mu \mathrm{l}$ of water. Two microliters of each DNA sample was amplified in $50 \mu \mathrm{l}$ of reaction buffer containing fgfr-1 primer $1\left(5^{\prime}\right.$-ATGGATTCTGTGGTGCCTTC-3') and primer 3 $\left(5^{\prime}\right.$-AACTGGAAAGAAGGAAGAAGGG-3'). This primer pair flanks the $P G K n e o$ insertion site and amplifies a 261 -bp fragment froin the wild-type $f g f r-1$ gene. Theoretically, these primers could also amplify an $\sim 2100$-bp fragment from the fgfr- $1^{\text {ex } 4}$ allele in heterozygous or homozygous embryos. However, under our PCR conditions, the amplification of this fragment was inefficient and not easily visualized by ethidium staining. DNA was also amplified using neo primer $1\left(5^{\prime}\right.$-AGAGGCTATTCGGCTATGACTG-3') and primer 2 (5'-TTCGTCCAGATCATCCTGATC-3') to detect the neo gene in the fgfr- $1^{\text {ex }}$ allele. In this case, a 431-bp fragment is detected in embryos heterozygous or homozygous for the fgfr- $1^{\text {ex }}$ allele, whereas no signal can be detected in wild-type embryos.

\section{Embryo analysis}

Mice heterozygous for the $f g f_{r}-1^{e x 4}$ allele were mated for timed pregnancies, with the day of the vaginal plug considered to be 0.5 day of development (E0.5). At the desired time points, we dissected embryos from decidua for photography and further analysis. For E8.5 and E9.5 embryos, we collected the visceral yolk sac for genotype determination by PCR. For histology studies, embryos were fixed in $4 \%$ paraformaldehyde or Bouin's fixative (Sigma) at $4^{\circ} \mathrm{C}$ for $1 \mathrm{hr}$, dehydrated through a graded alcohol series, and then embedded in paraffin. Sections of $6-\mu \mathrm{m}$ were prepared and stained with Harris hematoxylin and eosin according to standard procedures.

\section{In vitro culture of blastocysts}

Conditions for blastocyst culture were similar to those described (Hsu 1979), except that blastocysts were incubated individually in 24-well plates. Under these culture conditions, $\sim 70 \%$ of the blastocysts hatched from the zona pellucida and attached to petri dishes within $24 \mathrm{hr}$, another $25 \%$ attached within $48 \mathrm{hr}$, and the remaining $5 \%$ either died or were lost during changes of the culture medium. Blastocyst outgrowths were inspected daily and photographed to monitor their devel opment. After 6 days of culture, DNA was prepared for genotyping by PCR.

\section{Whole-mount in situ hybridization}

Embryos were collected and fixed in $4 \%$ paraformaldehyde for $8-14 \mathrm{hr}$ at $4^{\circ} \mathrm{C}$, followed by dehydration through a methanol series and storage at $-20^{\circ} \mathrm{C}$ until use. Embryos were then treated and hybridized to digoxygenin-labeled riboprobes essentially as described (Riddle et al. 1993). The Brachyury probe was synthesized from a plasmid containing a 716-bp fragment from the 3'-untranslated region (bp 1048-1764 of the published sequence) (Herrmann et al. 1990), which was PCR amplified and cloned into the PstI and EcoRI sites of Bluescript IIKS $|+|$. For riboprobe synthesis, this plasmid was linearized at the polylinker NotI site and transcribed with T3. The Shh probe was provided by Dr. Andrew McMahon (Echelard et al. 1993).

\section{Differentiation of ES cells in vivo}

ES cells heterozygous or homozygous for the fgfr- $1^{e x 4}$ mutation were trypsinized and suspended in PBS at a concentration of $10^{7}$ cells $/ \mathrm{ml}$. Cells $\left(10^{6}\right)$ were subcutaneously injected into 3 - to 5-week-old nude mice. The mice were sacrificed 3-4 weeks later, when tumors were $1-2 \mathrm{~cm}$ in diameter. The tumors were fixed in Optimal ${ }^{\star}$ Fix (American Histology Reagent Company, Inc.) and processed for histological sectioning.

\section{Acknowledgments}

We thank Mario Capecchi, En Li, Andrew McMahon, Teruhisa Tsuzuki, and Rudolph Jaenisch for their generous gifts of reagents, David Conner for information on PCR primers for the neo gene, and Terry Yamaguchi and Janet Rossant for communication of results prior to publication. We also thank Robert Cardiff for help with histological analysis of ES-cell-derived teratomas, and Anne Burke and David Chan for advice on wholemount in situ hybridization. We are grateful to Wallace McKeehan, Ed Laufer, Cliff Tabin, Malcolm Whitman, and members of the Leder laboratory for useful discussions and comments on the manuscript. A.W.-B. was a Howard Hughes Medical Institute Physician Research Fellow. M.M.S. was supported by a Special Fellowship from the Leukemia Society of America.

The publication costs of this article were defrayed in part by payment of page charges. This article must therefore be hereby marked "advertisement" in accordance with 18 USC section 1734 solely to indicate this fact.

\section{References}

Amaya, E., T.J. Musci, and M.W. Kirschner. 1991. Expression of a dominant negative mutant of the FGF receptor disrupts mesoderm formation in Xenopus embryos. Cell 66: 257270.

Amaya, E., P.A. Stein, T.J. Musci, and M.W. Kirschner. 1993. FGF signalling in the early specification of mesoderm in $\mathrm{Xe}$ nopus. Development 118: 477-487.

Basilico, C. and D. Moscatelli. 1992. The FGF family of growth factors and oncogenes. Adv. Cancer Res. 59: 115-165.

Berridge, M.J., C.P. Downes, and M.R. Hanley. 1989. Neural and developmental actions of lithium: A unifying hypothesis. Cell 59: 411-419. 
Burgess, W.H. and T. Maciag. 1989. The heparin-binding (fibroblast) growth factor family of proteins. Annu. Rev. Biochem. 58: 575-606.

Campbell, W.J., K.A. Miller, T.M. Anderson, J.D. Shull. and A. Rizzino. 1992. Expression of fibroblast growth factor receptors by embryonal carcinoma cells and early mouse embryos. In Vitro Cell. Dev. Biol. 28A: 61-66.

Cornell, R.A. and D. Kimelman. 1994. Activin-mediated mesoderm induction requires FGF. Development 120: 453-462.

Dell, K.R. and L.T. Williams. 1992. A novel form of fibroblast growth factor receptor 2. Alternative splicing of the third immunoglobulin-like domain confers ligand binding specificity. J. Biol. Chem. 267: 21225-21229.

Dionne, C.A., G. Crumley, F. Bellot, J.M. Kaplow, G. Searfoss, M. Ruta, W.H. Burgess, M. Jaye, and J. Schlessinger. 1990. Cloning and expression of two distinct high-affinity receptors cross-reacting with acidic and basic fibroblast growth factors. EMBO I. 9: 2685-2692.

Duan, D.S., S. Werner, and L.T. Williams. 1992. A naturally occurring secreted form of fibroblast growth factor (FGF) receptor 1 binds basic FGF in preference over acidic FGF. $I$. Biol. Chem. 267: 16076-16080.

Echelard, Y., D.J. Epstein, B. St-Jacques, L. Shen, J. Mohler, J.A. McMahon, and A.P. McMahon. 1993. Sonic hedgehog, a member of a family of putative signaling molecules, is implicated in the regulation of CNS polarity. Cell 75: 14171430.

Eisemann, A., J.A. Ahn, G. Graziani, S.R. Tronick, and D. Ron. 1991. Alternative splicing generates at least five different isoforms of the human basic-FGF receptor. Oncogene 6: 1195-1202.

Haub, O. and M. Goldfarb. 1991. Expression of the fibroblast growth factor-5 gene in the mouse embryo. Development 112: 397-406.

Hébert, J.M., C. Basilico, M. Goldfarb, O. Haub, and G.R. Martin. 1990. Isolation of cDNAs encoding four mouse FGF family members and characterization of their expression patterns during embryogenesis. Dev. Biol. 138: 454-463.

Hébert, J.M., M. Boyle, and G.R. Martin. 1991. mRNA localization studies suggest that murine FGF-5 plays a role in gastrulation. Development 112: 407-415.

Hemmati-Brivanlou, A. and D.A. Melton. 1992. A truncated activin receptor dominantly inhibits mesoderm induction and formation of axial structures in Xenopus embryos. $\mathrm{Na}$ ture 359: 609-614.

- 1994. Inhibition of activin receptor signaling promotes neuralization in Xenopus. Cell 77: 273-281.

Herrmann, B.G. 1991. Expression pattern of the Brachyury gene in whole-mount $T^{\text {Wis }} / T^{\text {Wis }}$ mutant embryos. Development 113: 913-917.

Herrmann, B.G., S. Labeit, A. Poustka, T.R. King, and H. Lehrach. 1990. Cloning of the $T$ gene required in mesoderm formation in the mouse. Nature 343: 617-622.

Hou, J., M. Kan, K. McKeehan, G. McBride, P. Adams, and W.L. McKeehan. 1991. Fibroblast growth factor receptors from liver vary in three structural domains. Science 251: 665-668.

Hsu, Y.C. 1979. In vitro development of individually cultured whole mouse embryos from blastocyst to early somite stage. Dev. Biol. 68: 453-461.

Johnson, D.E. and L.T. Williams. 1993. Structural and functional diversity in the FGF receptor multigene family. $A d v$. Cancer Res. 60: 1-41.

Johnson, D.E., P.L. Lee, J. Lu, and L.T. Williams. 1990. Diverse forms of a receptor for acidic and basic fibroblast growth factors. Mol. Cell. Biol. 10: 4728-4736.

Johnson, D.E., J. Lu, H. Chen, S. Werner, and L.T. Williams.
1991. The human fibroblast growth factor receptor genes: A common structural arrangement underlies the mechanisms for generating receptor forms that differ in their third immunoglobulin domain. Mol. Cell. Biol. 11: 4627-4634.

Kimelman, D. and M. Kirschner. 1987. Synergistic induction of mesoderm by FGF and TGF-beta and the identification of an mRNA coding for FGF in the early Xenopus embryo. Cell 51: 869-877.

Klagsbrun, M. 1989. The fibroblast growth factor family: structural and biological properties. Prog. Growth Factor Res. 1: 207-235.

LaBonne, C. and M. Whitman. 1994. Mesoderm induction by activin requires FGF-mediated intracellular signals. Development 120: 463-472.

Lawson, K.A. and R.A. Pedersen. 1992. Early mesoderm formation in the mouse embryo. In Formation and differentiation of early embryonic mesoderm (ed. R. Bellairs, J.W. Lash, and E.J. Sanders), pp. 33-46. Plenum Press, New York.

Lawson, K.A., J.J. Meneses, and R.A. Pedersen. 1991. Clonal analysis of epiblast fate during germ layer formation in the mouse embryo. Development 113: 891-911.

Li, E., T.H. Bestor, and R. Jaenisch. 1992. Targeted mutation of the DNA methyltransferase gene results in embryonic lethality. Cell 69: 915-926.

Mansour, S.L., K.R. Thomas, and M.R. Capecchi. 1988. Disruption of the proto-oncogene int-2 in mouse embryo-derived stem cells: a general strategy for targeting mutations to nonselectable genes. Nature 336: 348-352.

Mansour, S.L., J.M. Goddard, and M.R. Capecchi. 1993. Mice homozygous for a targeted disruption of the proto-oncogene int-2 have developmental defects in the tail and inner ear. Development 117: 13-28.

Mansukhani, A., D. Moscatelli, D. Talarico, V. Levytska, and C. Basilico. 1990. A murine fibroblast growth factor (FGF) receptor expressed in CHO cells is activated by basic FGF and Kaposi FGF. Proc. Natl. Acad. Sci. 87: 4378-4382.

Miki, T., D.P. Bottaro, T.P. Fleming, C.L. Smith, W.H. Burgess, A.M. Chan, and S.A. Aaronson. 1992. Determination of ligand-binding specificity by alternative splicing: Two distinct growth factor receptors encoded by a single gene. Proc. Natl. Acad. Sci. 89: 246-250.

Mohammadi, M., C.A. Dionne, N. Li, T. Spivak, A.M. Honegger, M. Jaye, and J. Schlessinger. 1992. Point mutation in FGF receptor eliminates phosphatidylinositol hydrolysis without affecting mitogenesis. Nature 358: 681-684.

Niswander, L. and G.R. Martin. 1992. Fgf-4 expression during gastrulation, myogenesis, limb and tooth development in the mouse. Development 114: 755-768.

Ornitz, D.M. and P. Leder. 1992. Ligand specificity and heparin dependence of fibroblast growth factor receptors 1 and $3 . \%$. Biol. Chem. 267: 16305-16311.

Orr-Urtreger, A., D. Givol, A. Yayon, Y. Yarden, and P. Lonai. 1991. Developmental expression of two murine fibroblast growth factor receptors, flg and bek. Development 113: 1419-1434.

Paterno, G.D., L.L. Gillespie, M.S. Dixon, J.M. Slack, and J.K. Heath. 1988. Mesoderm-inducing properties of INT-2 and kFGF: two oncogene-encoded growth factors related to FGF. Nature 336: 348-352.

Peters, K.G., J. Marie, E. Wilson, H.E. Ives, J. Escobedo, M. Del Rosario, D. Mirda, and L.T. Williams. 1992. Point mutation of an FGF receptor abolishes phosphatidylinositol turnover and $\mathrm{Ca}^{2+}$ flux but not mitogenesis. Nature 358: 678-681.

Peters, K., D. Ornitz, S. Werner, and L. Williams. 1993. Unique expression pattern of the FGF receptor 3 gene during mouse organogenesis. Dev. Biol. 155: 423-430. 
Riddle, R.D., R.L. Johnson, E. Laufer, and C. Tabin. 1993. Sonichedgehog mediates the polarizing activity of the ZPA. Cell 75: 1401-1416.

Ron, D., R. Reich, M. Chedid, C. Lengel, O.E. Cohen, A.M. Chan, G. Neufeld, T. Miki, and S.R. Tronick. 1993. Fibroblast growth factor receptor 4 is a high affinity receptor for both acidic and basic fibroblast growth factor but not for keratinocyte growth factor. I. Biol. Chem. 268: 5388-5394.

Slack, J.M., B.G. Darlington, L.L. Gillespie, S.F. Godsave, H.V. Isaacs, and G.D. Paterno. 1989. The role of fibroblast growth factor in early Xenopus development. Development 106: 7983.

Smith, J.C. 1989. Mesoderm induction and mesoderm-inducing factors in early amphibian development. Development 105: 665-677.

Stark, K.L., J.A. McMahon, and A.P. McMahon. 1991. FGFR-4, a new member of the fibroblast growth factor receptor family, expressed in the definitive endoderm and skeletal muscle lineages of the mouse. Development 113: 641-651.

Tam, P.P.L. 1989. Regionalisation of the mouse embryonic ectoderm: Allocation of prospective ectodermal tissues during gastrulation. Development 107: 55-67.

Thomas, K.R. and M.R. Capecchi. 1990. Targeted disruption of the murine int-1 proto-oncogene resulting in severe abnormalities in midbrain and cerebellar development. Nature 346: $847-850$.

Tybulewicz, V.L., C.E. Crawford, P.K. Jackson, R.T. Bronson, and R.C. Mulligan. 1991. Neonatal lethality and lymphopenia in mice with a homozygous disruption of the c-abl protooncogene. Cell 65: 1153-1163.

Vainikka, S., J. Partanen, P. Bellosta, F. Coulier, D. Bimbaum, C. Basilico, M. Jaye, and K. Alitalo. 1992. Fibroblast growth factor receptor-4 shows novel features in genomic structure, ligand binding and signal transduction. EMBO J. 11: 42734280.

Werner, S., D.S. Duan, C. de Vries, K.G. Peters, D.E. Johnson, and L.T. Williams. 1992. Differential splicing in the extracellular region of fibroblast growth factor receptor 1 generates receptor variants with different ligand-binding specificities. Mol. Cell. Biol. 12: 82-88.

Wilkinson, D.G., G. Peters, C. Dickson, and A.P. McMahon. 1986. Expression of the FGF-related proto-oncogene int-2 during gastrulation and neurulation in the mouse. Nature 324: 34-38.

Wilkinson, D.G., S. Bhatt, and B.G. Herrmann. 1990. Expression pattern of the mouse $T$ gene and its role in mesoderm formation. Nature 343: 657-659.

Xu, J., M. Nakahara, J.W. Crabb, E. Shi, Y. Matuo, M. Fraser, M. Kan, J. Hou, and W.L. McKeehan. 1992. Expression and immunochemical analysis of rat and human fibroblast growth factor receptor $(f \mathrm{lg})$ isoforms. I. Biol. Chem. 267: 1779217803.

Yamaguchi, T.P., R.A. Conlon, and J. Rossant. 1992. Expression of the fibroblast growth factor receptor FGFR-1/flg during gastrulation and segmentation in the mouse embryo. Dev. Biol. 152: $75-88$.

Yamaguchi, T.P., K. Harpal, M. Henkemeyer, and J. Rossant. 1994. fgfr-1 is required for embryonic growth and mesodermal patterning during mouse gastrulation. Genes \& Dev. (this issue).

Zimmer, Y., D. Givol, and A. Yayon. 1993. Multiple structural elements determine ligand binding of fibroblast growth factor receptors. Evidence that both Ig domain 2 and 3 define receptor specificity. J. Biol. Chem. 268: 7899-7903. 


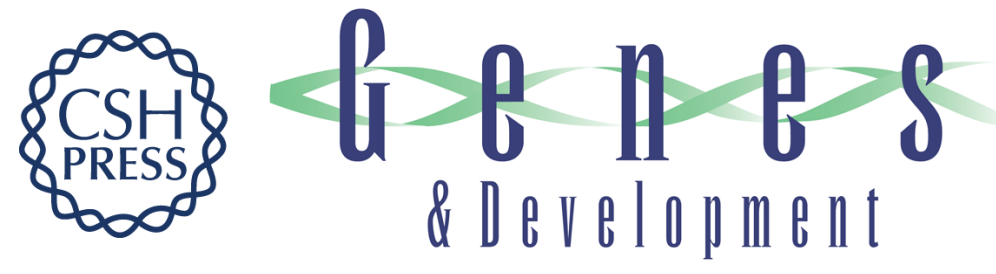

\section{Murine FGFR-1 is required for early postimplantation growth and axial organization.}

C X Deng, A Wynshaw-Boris, M M Shen, et al.

Genes Dev. 1994, 8:

Access the most recent version at doi:10.1101/gad.8.24.3045

References This article cites 55 articles, 26 of which can be accessed free at:

http://genesdev.cshlp.org/content/8/24/3045.full.html\#ref-list-1

License

Email Alerting

Service

Receive free email alerts when new articles cite this article - sign up in the box at the top right corner of the article or click here.

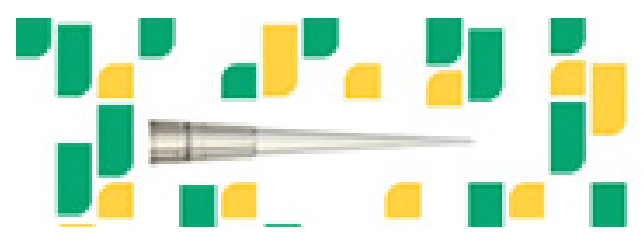

Focused on your science.

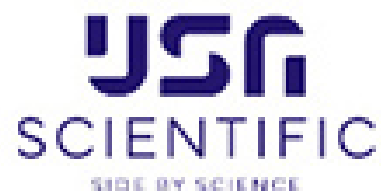

Copyright (c) Cold Spring Harbor Laboratory Press 